\title{
The Role of Analytical Frameworks for Systemic Research Design, Explained in the Analysis of Drivers and Dynamics of Historic Land-Use Changes
}

\author{
Claudia Coral * and Wolfgang Bokelmann \\ Department of Agricultural Economics, Thaer-Institute, Humboldt-University Berlin, 10099 Berlin, Germany; \\ w.bokelmann@agrar.hu-berlin.de \\ * Correspondence: coguerrc@cms.hu-berlin.de; Tel.: +49-30-2093-46332
}

Academic Editors: Shankar Sankaran, Pamela Buckle Henning, Timothy Ferris and Mary C. Edson Received: 14 January 2017; Accepted: 20 February 2017; Published: 24 February 2017

\begin{abstract}
Analytical frameworks provide the basic vocabulary of concepts and terms that may be used to construct the kinds of causal explanations expected of a theory. In addition, framework-based approaches are applied as a way of dealing with the complexity that arises in situations involving human interactions with the environment. This paper presents an example of an application of the "Analytical Framework for a Systemic Analysis of Drivers and Dynamics of Historical Land-Use Changes" with the purpose of showing the role of the selected analytical framework in the design of systemic research, namely as it is conceived and as it develops over time. This analytical framework helps to organize research by linking the theoretical questions to the empirical analysis, while serving as a platform for the construction of theoretical explanations, which represent the flow of knowledge in various contexts and conditions. In the context of systems research, the combination of an analytical framework with grounded theory approaches may allow researchers to achieve both creative thinking and novel outcomes, without losing a certain degree of coherence. We also hope to understand the real motives behind decision-making and dynamics of space and time in order to support the design of policies that take into account local differences.
\end{abstract}

Keywords: systemic research; systems thinking; methodology; analytical framework; land-use changes

\section{Introduction}

The usage of an analytical framework has been particularly effective in empirical research and offers several opportunities for the organization of research; however, no definition has been formally agreed upon. Indiana University Professor Elinor Ostrom, awarded the Nobel Prize for Economic Sciences, has proposed that the construction and use of a general framework could help to identify the elements a study is to consider, as well as the relationship of these elements to one another. Moreover, frameworks help to organize research and provide a general list of areas or variables that will be used in any type of analysis. Frameworks contribute meta-theoretical language, which enables scholars to discuss any particular theory or to compare theories. Many differences may also arise in the way these variables interact with each other, according to how they are analyzed or combined [1].

Ostrom points out that the difference between a framework and a model is that a model formulates a hypothesis related to a limited set of parameters and variables through simulation, experimentation, and prediction, among others, with the objective of exploring these assumptions in a systematic way with a limited number of outcomes [2]. Models constitute a more detailed manifestation of a general theoretical explanation, in terms of the functional relationships among independent and dependent variables relevant to or within a particular setting [3]. In contrast, a framework is a platform in which 
theories and models can be constructed [1]. In the case of our research, the "Analytical Framework for a Systemic Analysis of Drivers and Dynamics of Historical Land-Use Changes" [4,5] has been selected and used as a platform through which the causal explanations and relationships expected of a theory can be constructed.

Research on land-use changes has concentrated on the development of spatial models based on mechanistic reductionist approaches. Reductionist science has been applied in the field of agriculture for the creation of technologies and solutions directed towards increasing agricultural production and economic growth. However, human nature and all the motives behind human actions are often not taken into account, as is also often the case with the long term, unintended impacts of decisions, which may threaten humanity and contribute to environmental degradation [4]. Scientists have called for a new approach better able to manage complexity. Framework-based approaches are applied as a way to deal with this complexity [6]. However, as stated by Paul Cilliers (1994), "We cannot have complete knowledge of complex systems; we can only have knowledge in terms of a certain framework. We choose our frameworks. This choice need not be arbitrary in any way, but it does mean that the status of the framework (and the framework itself) will have to be continually revised" [6] (p. 442). Consequently, we begin at the level of a framework for analysis.

Some of the frameworks available in the literature on land-use change are the Analytical Framework for Disentangling the concept of Sustainable Land-Use [7], which takes into account agro-ecological components at policy, farm, and plot level; the Conceptual Framework for Analysing and Measuring Land-Use Intensity, which integrates three dimensions: (a) input intensity, (b) output intensity, and (c) the associated system-level impacts of land- based production (e.g. changes in carbon storage or biodiversity) [8]; the Analytical Framework For Understanding Land-Use Regime Shifts, which propose that the causes of land-use regime shifts can be understood by characterizing the preconditions (e.g., prevailing product demand and supply conditions; macroeconomic conditions and technology), triggers of change (new land-use policies, technological change and infrastructure development, demographic change or environmental, economic, or social shocks), and the self-reinforcing processes that maintain the new state [9]; and the Telecoupling framework, which takes distant forces into account in land-use change and builds on the concept of telecoupling (i.e., environmental and socioeconomic interactions among coupled systems over large distances) [10-12]; among others. Additionally, according to the DPSIR framework for instance, there is a chain of causal links starting with 'driving forces' (economic sectors, human activities) through 'pressures' (emissions, waste) to 'states' (physical, chemical and biological) and 'impacts' on ecosystems, human health and functions, eventually leading to political 'responses' (prioritisation, target setting, indicators) [13]. Other studies provide a review of micro-level drivers of land-use change (see [14]). However, the Analytical Framework for a Systemic Analysis of Drivers and Dynamics of Historical Land-Use Changes has been selected because it takes into account historical components, the cognitive factors inherent to the decisions makers, as well as bio-geographic and socio-economic components. It is based on systems thinking. In addition, it assumes that the land-use decision-making process is also driven by people's perceptions of the environment and of external reality [4,5]. In this sense, the application of this framework can contribute greatly to understanding the real motives behind land-use decision-making (see Section 2).

This paper is divided into three parts and aims to do the following: Section 2 explains the foundations, logic, and components of the "Analytical Framework for a Systemic Analysis of Drivers and Dynamics of Historical Land-Use Changes" [4,5]. Section 3 introduces the first application of this framework, specifically how the components of the framework were translated into empirical research questions and how research methods were selected to fulfill the requirements of the framework-for instance, how grounded theory as a method allows for a robust examination of the interrelationships among the various components of the framework, as well as integration of all categories of analysis to form theoretical explanations. The final section of this paper provides a discussion on the implications of these framing choices and methodology. 
The purpose of this paper is to demonstrate the role of the selected analytical frameworks in systemic research as it is conceived and as it may develop over time.

\section{Introduction to the Analytical Framework for a Systemic Analysis of Drivers and Dynamics of Historical Land-Use Changes}

This analytical framework was introduced for the first time in 2015 during the International Society for the Systems Sciences conference in Berlin, Germany [4,5]. The selected analytical framework is based on the "systems thinking" approach. Barry Richmond defined systems thinking as the art and science of making reliable inferences about behavior by developing an increasingly deep understanding of underlying structure [15,16]. Furthermore, Richmond also said that when taking a systems thinking approach, researchers position themselves such that they can "see both the forest and the trees; one eye on each" $[15,16]$. The new conceptualizations of systems thinking draw attention to the relationship between elements, as opposed to studying elements in isolation. For this reason, systems thinking focuses on interaction, entailment, dependencies, exchange, connections, relationships, and co-evolution [17] (p. 6).

For the purposes of this research, the system that is the object of study is the land system. Land systems are the result of human interactions with the environment. Land systems represent the terrestrial component of the earth system, which encompass all processes and activities related to the human use of land—including socioeconomic, technological, and organizational arrangements-as well as the benefits gained from land and the unintended social and ecological outcomes or externalities of social interactions [18]. The study of these systems requires great interdisciplinary effort. Studies of land-use changes have been included in agro-economic research because the changes in general agricultural conditions have social, environmental, and economic effects [19]. Land-use provides many economic and social benefits, but often comes at a substantial cost to the environment.

Recent research in agro-economic systems has included bio-geographic and socio-economic factors. The selected variables have been used to build multiple regression models for all the possible combinations of land use types, eco-regions, and levels of aggregation [20,21]. In other cases, these variables are used in the design and implementation of agent based models [22]. New strands of scientific research have concentrated on the use of remote sensing and other geographic information systems for crops and vegetation monitoring [23].

However, the cognitive factors inherent to the decision makers-in this case the landowners or land administrators-have often been overlooked. Some studies have recognized that land-use decisions, i.e., land-use choices, are also heavily influenced by drivers such as social constructions and needs, values, emotions, and the personal history of each decision-maker [24] (p. 53). Furthermore, some results show that the great majority of the lands are owned and managed by private owners who are not always responsive when processes of planning and legislation are concerned. For this reason, new ways of linking science and practice must be developed to effectively translate scientific evidence into sustainable solutions and practices [18] (p. 434). The lack of studies that take the reality of the farmers into account, in addition to economic and bio-geophysical elements, has led to the adoption of ill-conceived agrarian reforms, which have worked to the detriment of environmental conservation efforts and to the farmers' livelihoods and lives (unpublished data).

The individual landowner should be taken into account as a starting point from which to derive different systems perceptions. As Niklas Luhmann has said, one mind is a unique psychic system or system of consciousness (mind-thoughts) [25] (p. 10). This is shown graphically in the schematic representation of the analytical framework (see Figure 1): namely, in the central funnel, which represents the individual with his/her values, knowledge, beliefs, and thoughts. This framework calls for an understanding of individual incentives and motivations, integrating this understanding into community decision-making at a collective level, by identifying the drivers that contribute to the creation of a collective bond. The decision-making process is driven by people's perceptions of the environment and of external reality-how they construct their own mental models, which is also 
influenced by community processes. This is because individuals are not isolated, hence communal values and aspirations also influence their decisions.

Finally, the historical component is important because human history fundamentally informs the present by allowing us to understand the meaning of human actions and decisions.

2.1. Schematic Representation of the Analytical Framework for a Systemic Analysis of Drivers and Dynamics of Historical Land-Use Changes

Figure 1 shows a schematic representation of the analytical framework for the analysis of land-use change dynamics. This framework focuses on landowner choices or decisions, the values they assign to different outcomes and how these individual choices are reflected in the community and in the environment. In addition, it is based on the assumption that these choices are heavily influenced by social constructions, values, and the personal history of each decision maker $[4,5]$. This framework also assumes that the way in which people perceive the environment and external reality works to construct their mental models (cognitive representations of external reality). The central 'funnel' depicted in the middle of Figure 1 symbolizes how individuals filter all these different drivers into a decision $[4,5]$. These choices might reflect societal structures and processes of learning and interaction among a broad range of actors [17] (p. 10). In other words, the 'funnel' idea symbolizes the mechanism by which decisions are made. It is the role of the researcher to identify the adequate tools and methods to uncover this mechanism (see Discussion section).

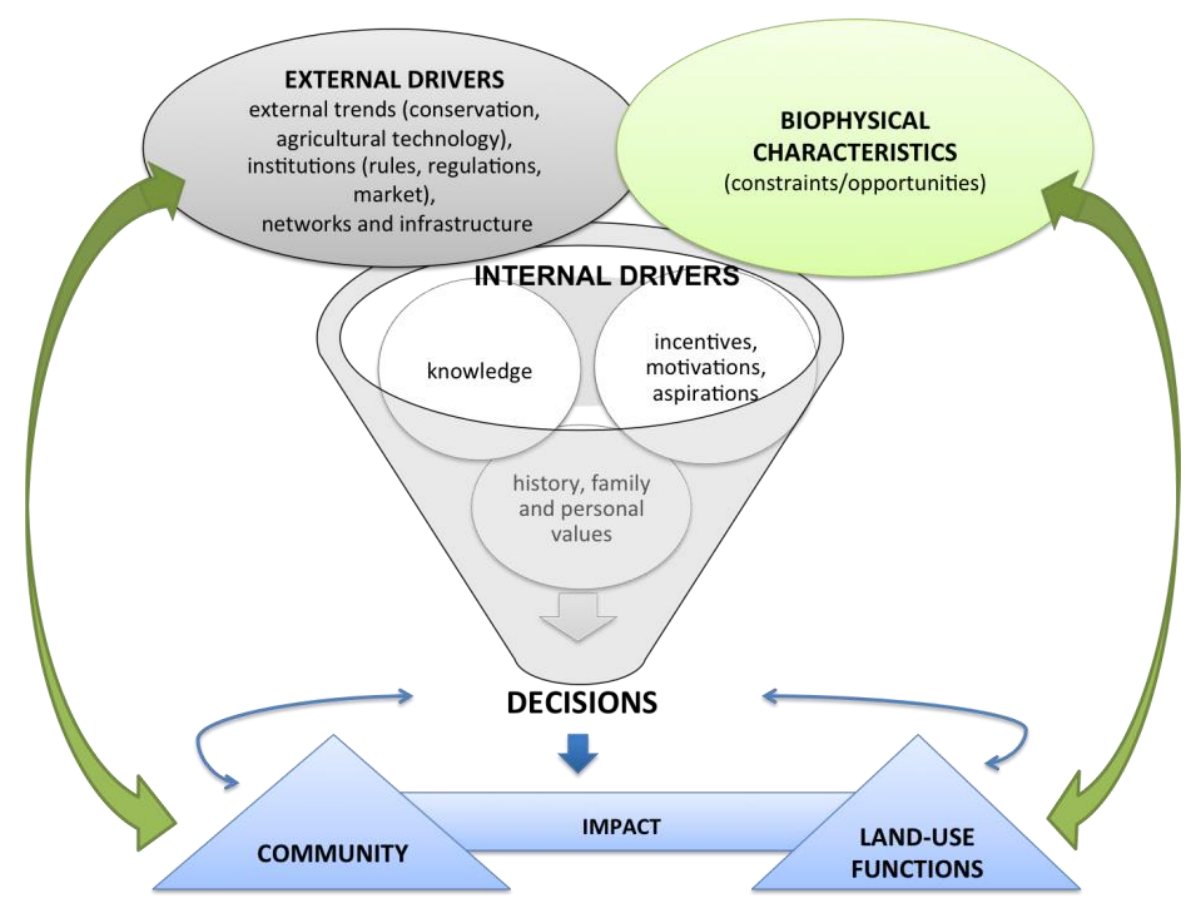

Figure 1. Analytical Framework for a Systemic Analysis of Drivers and Dynamics of Historical Land-Use Changes. Source: modified after $[4,5]$.

\subsection{Analytical Categories and Assumptions}

\subsubsection{External Drivers}

Landowner decisions are influenced by a number of so-called external drivers. These drivers are related to political factors, socio-economic factors, and social processes at the community level. Examples of these drivers are: conservation trends, agricultural reforms, innovation systems, agricultural technology, and formal and informal institutions such as markets or regulations, which 
also contribute to a final decision. These external factors are depicted with a gray circle on the left side of Figure $1[4,5]$.

\subsubsection{Biophysical Characteristics of the Environment}

This framework also assumes that the biophysical characteristics of the environment influence decision makers; these characteristics provide limitations to and requirements for agricultural production, for instance, and constitute constraints and/or opportunities. The framework assumes that present actions and decisions might again affect the environment and its biophysical characteristics, which might affect future decisions and system dynamics; this is shown graphically and symbolized by the green arrows in Figure $1[4,5]$.

\subsubsection{Internal Drivers}

Based on the assumption that land-use choices are heavily influenced by social constructions, values, and the personal history of each decision-maker [4,5], this category has been created to generate an appreciation of perspectives. Internal (to the human condition) drivers are represented by a 'funnel' (depicted in the middle of Figure 1). The idea of a filter is used because external drivers are perceived differently according to knowledge, beliefs, individual history, family and personal values, incentives, motivations, and aspirations (see Figure 1).

All these elements (internal, external drivers, and perceptions of the environment) filter into a land-use decision.

\subsubsection{Community}

"Community" symbolizes the relationship of each individual to his/her community and represents his/her social responsibility to this community. Individuals are not isolated; communal values and aspirations also influence decision-makers and, in return, individual beliefs may also influence communal values and aspirations [4].

\subsubsection{Land-Use Functions}

The framework also assumes that these decisions and choices impact land-use functions (goods and services provided by different land-uses), as well as the system as a whole [4].

In many cases, there is and is supposed to exist overlap between these analytical categories. The separation between internal and external drivers was seen as a way to identify and differentiate how people perceive both external reality and changes in the environment.

\subsubsection{Linkages and Inter-Linkages}

In general, within the schematic representation of this analytical framework, arrows provide assumptions about relationships. The link between the individual (cognitive system) and the community (social system) is realized through communication, or communicative events, which is symbolized by the blue arrows in Figure 1. In addition, the large, green arrows symbolize process and dynamics. Regarding this dynamic state, as stated by Mead in 1934, "Actions are embedded in interactions-past, present, and imagined future. Thus actions also carry meaning. Actions might generate further meanings, with regard to both further actions and the interactions in which they are embedded" [26]. These actions and interactions and meaning are precisely what are of interest in systemic research, in addition to the major set of conditions that affect people's perspectives. These interactions might affect the future course of action. For instance, present actions and decisions might also affect the environment and its biophysical characteristics, which might affect future decisions and system dynamics; this is shown graphically and symbolized by the green arrows in Figure 1. 


\subsection{Historical Perspective}

A historical approach is taken, as changes occur not only spatially but temporally. How land-use changes over time and how systems have co-evolved with the changing environment-for instance, through processes of social learning - plays a crucial role in systems research [4,5] (see Figure 2). In fact, past memories and recollections also enter directly or indirectly into action [27]. History offers the opportunity to understand the present- the choices and the circumstances that have shaped us. Figure 2 shows how this set of elements may vary over time, hence the need for an analysis of these elements in historical context.

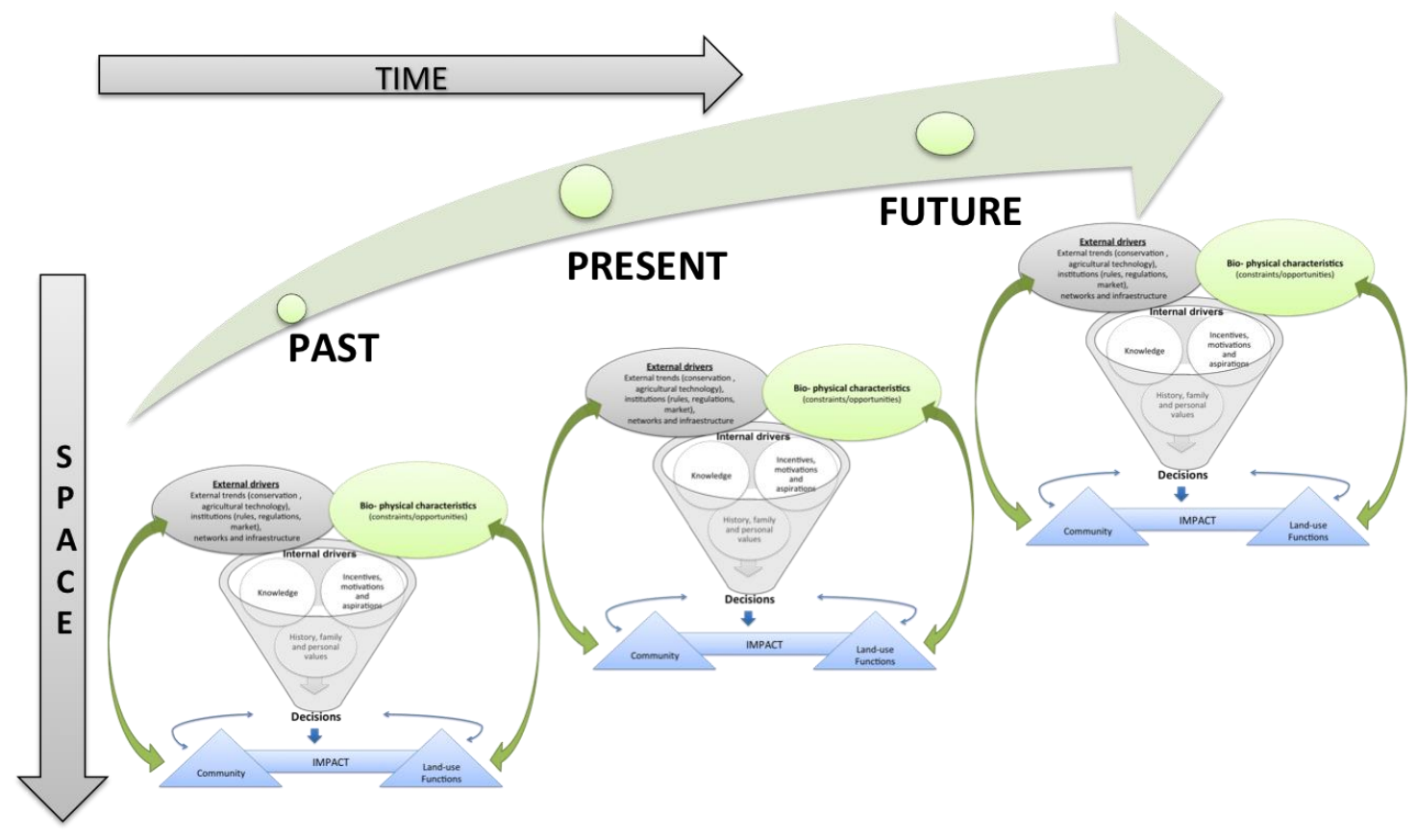

Figure 2. Schematic Representation of the Historical Analysis. Source: modified after [4,5].

\section{Research Design for the Case Study "Systemic Evaluation of the Drivers and Dynamics of Historical Changes of Land-Use in the Northwest of Pichincha, Ecuador"}

The northwest of Pichincha, Ecuador has been selected because of its large quantity of cloud forests, its conservation history, the emergence of interesting models for sustainable agriculture, and the creation of private conservation networks.

Areas of Ecuadorian cloud forest have been identified as great biodiversity reservoirs. They are necessary for water source protection because of their ability to capture and distribute water to lower areas [28].

The selected study area, Mindo-Nambillo Protected Forest, experiences great pressure from agricultural frontier expansion (mainly cattle, small-scale feeding on natural grass), logging, extraction of natural resources, hunting, tourism, and construction related to urbanization. Nowadays, the fragmentation of remnant forest is important, but it is counteracted by both a strong conservationist movement and foreign investment in conservation and ecotourism activities. Much of the cloud forest around Mindo is protected in the Mindo-Nambillo Protected Forest thanks to civil society initiatives. However, even if most of the forest is closed to the public, there are ample private reserves and publicly accessible trails throughout Mindo's cloud forests.

According to exploratory interviews conducted with different actors and according to a literature review, the lack of local micro-institutions to regulate the use of the forest, the lack of secure property rights for historical reasons, and heterogeneity the of the community due to migration (the result of an economic and political crisis) may be drivers of deforestation in private, forested areas. On one hand, 
programs of payments for ecosystem services and ecotourism-including bird watching and other sustainable projects led by local, national, and international NGOs and foundations-might be drivers that lead to nature conservation. On the other hand, traditional agricultural activities such as home gardening or agroforestry might be threatened by a combination of government policies and other external conservation trends (external drivers), which somehow hinder the conception of sustainable income-generating solutions and food security. In the next section, we will introduce the research design of the first application of the previously introduced analytical framework.

\subsection{Research Questions and Aims}

In accordance with taking a historical perspective, as suggested by our analytical framework, three relevant periods of change have been identified. The first phase begins in 1964. This period was marked by the Land Reform and Colonization Law enacted in 1964. The purpose of this law was to correct the flaws of the agrarian structure, as well as to improve land distribution and utilization. Within this reform, the Ecuadorian Institute of Land Reform and Colonization (IERAC) demobilized the peasantry by fostering colonization [29] (p. 592). In general terms, land reform permitted expansion of arable land (two million hectares) in only 20 years [29] (p. 593). The agrarian reform laws considered forestland 'unproductive' and thus available for occupation or expropriation. As a result, property owners were forced to clear 50 to 80 percent of the forest to avoid invasion or expropriation, which were trends at the time. In addition, colonists cleared land to demonstrate that they were 'using' it, as required by the law, with the objective of obtaining property titles. As a result, by the early 1990s, when this law was changed, a large portion of primary forest was already reduced to pasture and cropland [30].

The second period is characterized by incipient agriculture activities and logging, following the agrarian reform and until the creation of the protected forest in 1988.

Finally, the third period began in the 1990s with the beginning of the touristic boom, the opening of a paved road, and the designation of this area as Important Birth Area (IBAS) in 1997 [31].

Each of the analytical categories of the selected framework were translated into empirical research questions, which tell us which data to collect and what to look for in data analysis.

The research questions facilitated by the analytical framework are:

- What have been historic land-use changes in this area?

- What factors have influenced the landowner and land manager decisions about land-use?

- $\quad$ socioeconomic drivers (external drivers)

- $\quad$ economic drivers; (including migration)

- institutional/historical drivers (e.g., agrarian reforms, conservation policies)

- $\quad$ social drivers (e.g., social constructions)

- drivers related to the environment

- biophysical characteristics of the land

- drivers related to the psychic system (internal drivers: individual perception of external reality)

- cognitive drivers (personal needs, values, and emotions; past experiences, beliefs, and assumptions; perceptions-perceived risks and benefits of different land-uses, among others)

- individual history

- individual history of each decision-maker

- By which mechanism have these factors influenced historical land-use changes in this area? 
Since this study is explorative in nature, the research questions are framed in a manner that provides the researchers with some degree of flexibility and freedom to explore the topic in depth and to ask further questions based on incoming data.

Within this research, we expect to create a middle-range theory of human and land transformations and to generate knowledge in the way the already aforementioned drivers trigger historic processes (including changes in practices and changes in understanding and learning), land-use changes, and dynamics and their implications for nature conservation and human development. Methodologically, we aim to test the utility of the Analytical Framework for a Systemic Analysis of Drivers and Dynamics of Historical Land-Use Changes and its assumptions and to provide researchers with comparable data in the field of land-use changes that take into account decision-making processes and the set of conditions that drives these decisions. This data should be able to build upon existing knowledge, as well as to represent flows of knowledge in various contexts and conditions.

\subsection{Methods}

Firstly, for each of the research questions, decisions are made on the type of empirical research and methodologies to be used for analysis. As already mentioned, we take a historical approach. For this reason, the question of "what historic land-use changes have occurred in this area?" (first research question) is partly answered through the analysis of secondary data. The reconstruction of the past is conducted by making use of historical data, such as written documents, legal documents, oral narratives, satellite images, stories, songs, and landscapes that can reveal traces of the past (see $[32,33])$. This reconstruction of the past is also used to answer the second question of "what factors have influenced landowner and land manager decisions about land-use?"; specifically, to identify general external drivers (socioeconomic drivers) and general biophysical characteristics of the land (environmental drivers) in this specific area. The reconstruction of the past is not based only on secondary data, since our data collection aims to generate the appreciation of perspective-how external reality is perceived and how people's mental models $[34,35]$ change over time. Cognitive drivers (internal drivers) such as personal needs, values and emotions, past experiences (individual history), beliefs, perceptions of external reality, and assumptions are collected. For this purpose, we decided to undertake interviews with landowners in the area of the northwest of Pichincha following the techniques and procedures proposed by Corbin and Strauss (2015) [36]. Interviews lasted an average of one hour; the selection of participants followed the process of data collection called theoretical sampling [36] (pp. 135-152), which is directed by evolving theory rather than by predetermined population. In other words, the sampling of additional incidents, events, activities, and populations is directed by evolving theoretical constructs. This set of procedures consists of visiting certain places, contacting individuals, and creating opportunities or maximizing opportunities to discover concept variations and strengthen categories, as well as their properties and dimensions [36]. In grounded theory research, there is an identified population-for instance, landowners of the studied area-but the rest remains open. Analysis begins immediately following the first data collection. The identified concepts will generate questions, and these questions will lead to more data collection with the purpose of learning more about said concepts. This process continues until the point at which major categories are fully developed, show variation, and are integrated [36] (p. 135). The selection of semi-structured interviews allowed us to keep a certain degree of coherence between the concepts of interest to the research. Nevertheless, during the interviews we offered the space and freedom for open dialogue. In addition, we maintained an openness to the emergence of new concepts. In many cases, it was not necessary to use a guide for questions, because the participants, while telling us life and 'land' stories, covered many of the aspects and added new perspectives and concepts. In these cases, we obtained valuable narratives (individual history), which proved to be a successful method once the interviewer had gained the confidence of the interviewee. This method motivated participants to externalize their beliefs, knowledge, and perceptions of reality (mental models). 
Secondly, the objective of our research is not only to have a simple list of drivers (descriptive), but also to find "the mechanism by which these drivers have influenced historical land-use changes in this area" (last research question), in order to construct an emergent explanatory theory originating from the data. The framework itself justifies the selection of grounded theory as a method, since the framework itself does not explain this mechanism; this explanation is derived from the data. For this purpose, the techniques and procedures for developing grounded theory (constant comparative analysis, theoretical sampling, and theoretical coding) (see [36]) are also selected to analyze the interviews, as they enabled us to obtain general concepts and enable the development of a theoretical explanation that goes beyond the known, offering a new vision of phenomena and experiences [36] (p. 6). The selected methods of analysis provide tools for an examination of interactions and relations. These techniques can also be used to reveal the beliefs and meaning that form the foundation of actions, decisions, and behaviors, both rational and irrational. Moreover, these techniques allow us to demonstrate how logic and emotions influence the way people respond to certain circumstances or manage problematic situations [36] (p. 11). In addition, these procedures guide the researcher in examining how action-interaction is linked to the conditions to which people respond (process and context) [36] (p. 172).

The preexistence of an analytical framework to assist in organizing research does not constitute a limitation to the development of grounded theory. Corbin and Strauss expressed that a common basis for discussion, conflict, negotiation, or the development of knowledge grounded in practice cannot exist without a common conceptual language [36] (p. 26). Nevertheless, this conceptual language is considered provisional and may be subject to change. A more detailed discussion about this issue is found below in the discussion section.

For the qualitative analysis of the data, we used the software MAXQDA12.

\section{Discussion}

The framework itself is not explanatory, but this is also not its purpose. It is taken as the starting point of the research. Its function in this research is also to link the theoretical question to the empirical analysis, by summarizing our assumptions or theoretical knowledge about relevant empirical phenomena, as these must be tested and empirically investigated. The components of this framework translate into empirical research questions that tell us what data to collect and what to look for in data analysis. As stated by Cilliers (1994), we cannot have complete knowledge of complex systems; we can only have knowledge in terms of a certain framework, which is chosen by the researchers. This choice need not be somehow 'arbitrary'; this implies that the status of the framework (and the frame-work itself) will have to be continually revised [6] (p. 257). In view of this complexity, there is a need to frame the research and to provide the researcher with some starting point for said research. We take the individual landowners as a starting point from which to derive different systems perceptions. This implies that individual decision-making does play a role, as decisions might reflect societal structures and processes of learning and interaction among a broad range of actors.

In later stages, the research requires a robust examination of the interrelationships among the various components of the system being studied, as well as between the system and the larger environment. The aim of the research is to integrate all categories of analysis to form theoretical explanations. It suggests focusing on interaction, entailments, dependencies, exchange, connections, relationships, and co-evolution. From our point of view, these can only be derived from data. In this sense, the invariant components of the framework are the analytical categories and the way it allows for linkage, as well as the lens through which the system is seen-a shift towards systems thinking. However, the specific relationships between concepts, actions, and interactions will vary from case to case, as this action-interaction is located in the web of conditions and consequences that surrounds it (context). In fact, a key characteristic of this framework is the flexibility to represent the flow of knowledge in various contexts and conditions. In this specific research, the framework includes the possibility of expanding as knowledge is gained. As stated by Corbin and Strauss (2015), it is necessary 
to frame the research question or questions in a manner that provides the investigator with sufficient flexibility and freedom to explore a given topic in some depth [36] (p. 35). Data collection should be open for anything not included in the analytical framework but relevant for research. In this regard, the framework itself justifies the decision to select the techniques and procedures for the development of grounded theory because these methods allow for the emergence of new concepts based on the experience from the field.

Furthermore, the utilization of this analytical framework leads to a consideration of the intended and unintended impacts of actions and decisions, as the set of conditions affecting people's perspectives and interactions might affect the future course of action in ways that are often unpredictable, hence the importance of historical perspective. For instance, if overgrazing leads to desertification, political and individual decisions will change as changes in practice, understanding, and learning occur. The analysis of these processes can give insight into certain patterns and certain knowledge, which can contribute to the improvement of community processes, the design of policies, and the conception of sustainable solutions and alternatives with more grounded knowledge.

The preexistence of an analytical framework that facilitates the organization of the research does not hinder the construction of a grounded theory. As Corbin and Strauss have emphasized, the knowledge has evolved in light of experience and without a common conceptual language, there is not yet a foundation for discussion, conflict, negotiation, or the development of a knowledge-based practice [36] (p. 26). In this way, they admit that the analytical work needs a proper measure of conceptual language. However, this language is considered provisional and subject to change and modification [36] (p. 26).

A discussion of this issue is to be found in Timmermans and Tavory (2012), where they explain that abduction is also found in grounded theory methodology. Abduction assumes extensive familiarity with existing theories from the very beginning and throughout all stages of research, rather than engaging with scientific literature at the end of the research, as suggested by pure inductive approaches [37] (p. 173). They assume that, in practice, we have only partial access to the field and to shaping the way in which our interlocutors interact. However, this does not mean that we should assign a dominant role to fixed, generic identity categories, but to switch from induction to abduction in a way that theoretical references are foregrounded to set up "empirical puzzles" [37] (p. 173). In this sense, unanticipated and surprising observations, so named by Timmermans and Tavory, are strategic. They depend on a theoretically sensitized observer who recognizes their relevance and is able to stimulate the emergence of innovative and original theoretical contributions [37] (p. 173). Researchers follow the methodological guidance of grounded theory because it can lead to a novel theory that emerges following careful methodological steps, such as those proposed by Strauss and Corbin (2015) [37] (p. 177). According to Timmermans and Tavory, the question of whether grounded theory (in the variant of Strauss and Corbin) contains an abductive research logic can therefore be answered affirmatively. However, grounded theory does not only contain the logic of abductive reasoning but also that of qualitative induction [37]. In the context of systems research, we have found that a combination of an analytical framework with grounded theory methods may allow the researcher to achieve creative thinking and novel outcomes, without losing a certain degree of coherence.

In conclusion, in this specific study, the aforementioned techniques and procedures are not only used to identify the drivers of land-use change, but also to find the mechanism by which these factors have influenced historical land-use changes in the area. In the context of political science, it has been stated by Tilly and Goodin (2009) that mechanisms form a delimited class of events that change relations between specified sets of elements in identical or closely similar ways over a variety of situations [38] (p. 442). In other words, mechanisms tell us how changes happen, how actors relate and intervene, how individuals come to believe in certain ideas, and what they draw from past experience under certain conditions. The resulting theory of human and land transformations aims at a focus on interaction, entailment, dependencies, exchange, connections, relationships, as well as the 
co-evolution of human and natural systems. Furthermore, it aims to understand the motives behind decision-making — for this purpose, dynamics of space, time, and human choice play a role.

\section{Conclusions}

A common analytical framework provides a platform on which theories and methods can be constructed. The Analytical Framework for a Systemic Analysis of Drivers and Dynamics of Historical Land-Use Changes has been recommended in situations that involve changes of land-use. This analytical framework is rooted in systems thinking and aims to increase knowledge about land systems. It is taken as the starting point of the research, as it facilitates the linkage between the theoretical question and the empirical analysis. In addition, it constitutes a flexible framework that can represent the flow of knowledge in various contexts and conditions.

The utilization of an analytical framework combined with grounded theory techniques and procedures may allow researchers to achieve creative thinking and novel outcomes, without losing a certain degree of coherence.

Further efforts are needed to revise and strengthen this analytical framework through future applications, as the status of the framework and the framework itself will have to be continually revised. We consider the possibility of expanding the framework as knowledge is gained.

Many open questions remain in the literature about the role of analytical frameworks in systemic research. Future research must be relevant for the design of policies that take into account local differences. Most importantly, we hope to understand the real motives behind decision-making and dynamics of space and time, in order to avoid the application of solutions and measures considered valid for every situation without taking into account local realities (one size fits all), which in some cases has had detrimental impact on the environment and on rural communities.

Acknowledgments: The author thanks the support of the Secretary of Higher Education, Science, Technology and Innovation (SENESCYT) and the Ecuadorian Institute for the Promotion of Human Talent.

Conflicts of Interest: The authors declare no conflict of interest.

\section{References}

1. Ostrom, E. A general framework for analyzing sustainability of social-ecological systems. Science 2009, 325, 419-422. [CrossRef] [PubMed]

2. Ostrom, E. Institutional analysis and development: Elements of the framework in historical perspective. In Historical Developments and Theoretical Approaches in Sociology in Encyclopedia of Life Support Systems (EOLSS); Crothers, C., Ed.; Eolss Publishers: Oxford, UK, 2010.

3. McGinnis, M.D.; Ostrom, E. Social-ecological system framework: Initial changes and continuing challenges. Ecol. Soc. 2014, 19, 30. [CrossRef]

4. Coral, C. Chapter 14: Analytical Framework for a Systemic Analysis of Drivers and Dynamics of Historical Land-Use Changes: A Shift Toward Systems Thinking. In Balancing Individualism and Collectivism to Support Social and Environmental Justice; Contemporary Systems Thinking Series; (In Press)

5. Coral, C. Analytical Framework for a Systemic Analysis of Drivers and Dynamics of Historical Land Use Changes: A Shift towards Systems Thinking. In Presented at the International Society for the Systems Sciences (ISSS) Conference, Berlin, Germany, 30 July-7 August 2015.

6. Cilliers, P. Complexity, Deconstruction and Relativism. Theory Cult. Soc. 2005, 22, 255-267. [CrossRef]

7. Kruseman, G.; Ruben, R.; Kuyvenhoven, A.; Hengsdijk, H.; van Keulen, H. Analytical framework for disentangling the concept of sustainable land use. Agric. Syst. 1996, 50, 191-207. [CrossRef]

8. Erb, K.-H.; Haberl, H.; Jepsen, M.R.; Kuemmerle, T.; Lindner, M.; Müller, D.; Verburg, P.H.; Reenberg, A. A conceptual framework for analysing and measuring land-use intensity. Curr. Opin. Environ. Sustain. 2013, 5, 464-470. [CrossRef] [PubMed]

9. Ramankutty, N.; Coomes, O.T. Land-use regime shifts: an analytical framework and agenda for future land-use research. Ecol. Soc. 2016, 21, 1. [CrossRef] 
10. Liu, J.; Hull, V.; Batistella, M.; DeFries, R.; Dietz, T.; Fu, F.; Hertel, T.W.; Izaurralde, R.C.; Lambin, E.F.; et al. Framing sustainability in a telecoupled world. Ecol. Soc. 2013, 18, 26.

11. Friis, C.; Nielsen, J.Ø. Exploring the potential of the telecoupling framework for understanding land change. THESys Discussion Papers 2014; IRI THESys: Berlin, Germany.

12. Friis, C.; Nielsen, J.Ø.; Otero, I.; Haberl, H.; Niewöhner, J.; Hostert, P. From teleconnection to telecoupling: taking stock of an emerging framework in land system science. J. Land Use Sci. 2015, 1-23. [CrossRef]

13. Kristensen, P. The DPSIR Framework. In Paper presented at the 27-29 September 2004 workshop on a comprehensive / detailed assessment of the vulnerability of water resources to environmental change in Africa using river basin approach; National Environmental Research Institute, Denmark, Department of Policy Analysis, European Topic Centre on Water, European Environment Agency, UNEP Headquarters: Nairobi, Kenya, 2004.

14. Hettig, E.; Lay, J.; Sipangule, K. Drivers of Households' Land-Use Decisions: A Critical Review of Micro-Level Studies in Tropical Regions. Mimeo; German Institute of Global and Area Studies (GIGA): Hamburg, Germany, 2015.

15. Richmond, B. Systems Dynamics/Systems Thinking: Let's Just Get On With It. In Proceedings of the International Systems Dynamics Conference, Sterling, UK, 11-15 July 1994.

16. Arnold, R.D.; Wade, J.P. A Definition of Systems Thinking: A Systems Approach. Procedia Comp. Sci. 2015, 44, 669-678. [CrossRef]

17. Darnhofer, I.; Gibbon, D.; Dedieu, B. Farming Systems Research: An approach to inquiry. In Farming Systems Research into the 21st century: The New Dynamic; Springer Science + Business Media: Dordrecht, The Netherlands, Chapter 1; 2012; pp. 3-31.

18. Verburg, P.H.; Erb, K.H.; Mertz, O.; Espindola, G. Land System Science: between global challenges and local realities. Curr. Opin. Environ. Sustain. 2013, 5, 433-437. [CrossRef] [PubMed]

19. Casanova, L.; Martínez, J.; López, S.; López, G. De von Bertalanffy a Luhmann: Deconstrucción del concepto "agroecosistema" a través de las generaciones sistémicas. Rev. Mad 2016, 35, 60-74. (In Spanish) [CrossRef]

20. De Koning, G.H.J.; Veldkamp, A.; Fresco, L.O. Land use in Ecuador: A statistical analysis at different aggregation levels. Agric. Ecosyst. Environ. 1998, 70, 231-247. [CrossRef]

21. De Koning, G.H.J.; Verburg, P.H.; Veldkamp, A.; Fresco, L.O. Multi-scale modelling of land use change dynamics in Ecuador. Agric. Syst. 1999, 61, 77-93. [CrossRef]

22. Mena, C.F.; Walsh, S.J.; Frizzelle, B.G.; Yao, X.; Malanson, G.P. Land Use Change on Household Farms in the Ecuadorian Amazon: Design and Implementation of an Agent-Based Model. Appl. Geogr. 2011, 31, $210-222$. [CrossRef] [PubMed]

23. Boris, T.; Meyer, H.; Nauss, T.; Bendix, J. Projecting land-use and land-cover changes in a tropical mountain forest of Southern Ecuador. J. Land Use Sci. 2014, 9, 1-33.

24. Hutchison, E.; Charlesworth, L. Theoretical Perspectives on Human Behavior. In Dimensions of Human Behavior: Person and Environment; Hutchison, E., Ed.; SAGE Publications, Inc.: Thousand Oaks, CA, USA, 2007; Chapter 2; Volume 2, pp. 46-88.

25. Moeller, H. Luhmann Explained: From Soul to Systems; Ideas Explained Series; Open Court Publishing Company: Peru, Illinois, 2006; Volume 3.

26. Mead, G.H. Mind, self, and society. In Works of Georg Hebert Mead; Morris, C.W., Ed.; University of Chicago Press: Chicago, IL, USA, 1962; Volume 2.

27. Dewey, J. The Quest for Certainty; Minton Balch And Company: New York, NY, USA, 1929.

28. Museo Ecuatoriano de Ciencias Naturales (MECN); Ecosistemas del Distrito Metropolitano de Quito (DMQ). Serie de Publicaciones del Museo Ecuatoriano de Ciencias Naturales (MECN)_Fondo Ambiental del MDMQ; Publicación Miscelánea 6; 1-Imprenta Nuevo Arte: Quito, Ecuador, 2009; 51p. (In Spanish)

29. Bréton solo de Zaldívar, V. From Agrarian Reform to Ethnodevelopment in the Highlands of Ecuador. J. Agrar. Chang. 2008, 8, 583-617. [CrossRef]

30. Mecham, J. Causes and Consequences of Deforestation in Ecuador. Centro de Investigacion de los Bosques Tropicales-CIBT: Quito, Ecuador, 2001; Available online: http://www.rainforestinfo.org.au/projects/ jefferson.htm (accessed on 23 February 2017). 
31. Portugal, V. Tesis Ciencias Económicas y Financieras: La Influencia de los Derechos de Propiedad Intelectual en la Conservación y Uso Sustentable de los Recursos Genéticos en la Parroquia de Mindo; Escuela Politècnica Nacional: Quito, Ecuador, 2006; Available online: http://bibdigital.epn.edu.ec/handle/15000/218 (accessed on 1 December 2016). (In Spanish)

32. Jupp, V. The SAGE Dictionary of Social Research Methods; SAGE Publications Ltd.: London, UK, 2006.

33. Cronon, W. Learning to Do Historical Research: A Primer for Environmental Historians and Others. Available online: http:/ / www.williamcronon.net/researching/ (accessed on 1 December 2016).

34. Jones, N.A.; Ross, H.; Lynam, T.; Perez, P.; Leitch, A. Mental models: An interdisciplinary synthesis of theory and methods. Ecol. Soc. 2011, 16, 46. [CrossRef]

35. Jones, N.A.; Ross, H.; Lynam, T.; Perez, P. Eliciting mental models: A comparison of interview procedures in the context of natural resource management. Ecol. Soc. 2014, 19, 13. [CrossRef]

36. Corbin, J.M.; Strauss, A.L. Basics of Qualitative Research: Techniques and Procedures for Developing Grounded Theory; SAGE Publications, Inc.: Thousand Oaks, California, 2015; p. 456.

37. Timmermans, S.; Tavory, I. Theory Construction in Qualitative Research. Sociol. Theory 2012, 30, 167-186. [CrossRef]

38. Tilly, C.; Goodin, R.E. Overview of Contextual Political Analysis-It Depends. In The Oxford Handbook of Political Science; Goodin, R.E., Ed.; Oxford University Press Inc.: New York, NY, USA, 2009; Chapter 22.

(c) 2017 by the authors. Licensee MDPI, Basel, Switzerland. This article is an open access article distributed under the terms and conditions of the Creative Commons Attribution (CC BY) license (http://creativecommons.org/licenses/by/4.0/). 